cisa para comprender la memoria e identidad de las regiones, las ciudades y los pueblos y sus respectivos paisajes.

$>$ La intervención conservativa realizada en el territorio, los sitios, parques, lugares, edificios, obras de arte y objetos de la ciencia y de la técnica del pasado debe tender en el momento actual a la recuperación del espacio histórico desde la contemporaneidad y a la restauración democrática dirigida por los profesionales y los técnicos y participada por todos los colectivos de la sociedad.

> Finalmente, este congreso eleva a las autoridades y especialmente en este territorio a las de Castilla y León, su solicitud para inventariar los luga- res y objetos industriales, técnicos y científicos con el fin de proceder a su selección y para crear programas de conservación que transmitan al futuro este valioso tesoro material, ya inmerso en el acervo cultural de la colectividad.

$>$ De igual manera, se eleva a las administraciones correspondientes la petición de que el conocimiento del Patrimonio se introduzca en los diferentes niveles educativos para que nuestros niños y jóvenes puedan apreciarlo como propio y lo entiendan como signo de orgullo, estímulo e identificación.

\title{
La proliferación de lugares de exposición en las últimas décadas exige replanteamientos espaciales
}

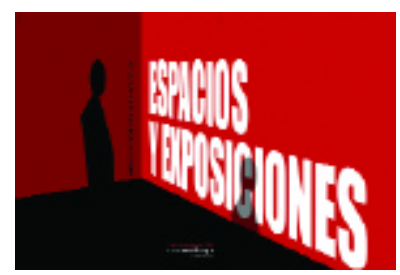

Entre los días 2 y 5 del pasado mes de noviembre, se celebró en el Centro de Arte Contemporáneo (CAC) de Málaga el VIII Seminario de Bienes Culturales: Espacios y Exposiciones, organizado por el Colegio de Arquitectos de Málaga.

En la presentación del Seminario, con representación de las distintas instituciones colaboradoras, y moderada por el director del Seminario, Francisco Rafael Luque, tanto la Catedrática de Historia del Arte de la Universidad de Málaga, Rosario Camacho, como Fernando Francés, director del CAC MÁLAGA y Bernardo Laniado-Romero, director del Museo Picasso Málaga, manifestaron la pertinencia de la temática y contenido del Seminario, dada la proliferación de museos, salas y lugares de exposición de las últimas décadas, la cual hace necesarios estudios de los planteamientos espaciales, actividades y actuaciones a realizar en estos contenedores.

La ponencia de Francisco Rafael Luque García fijó el marco inicial, al hablarnos en su conferencia sobre la Ciudad de Berlín, un ejemplo de ciudad que articula sus espacios expositivos como referentes que completan y definen su itinerario urbano físico e histórico. Rosa Domínguez, en su conferencia Arquitectura y ordenación del espacio expositivo, estableció los referentes históricos de los actuales espacios de exposición, haciendo, asimismo, especial énfasis en el comportamiento del público dentro de ellos y realizando un recorrido por algunos ejemplos actuales de contenedores expositivos. La intervención del escenógrafo Antonio Marín resaltó la importancia de las escenografías en estos espacios, así como los procesos para su creación, en su conferencia Diseño y Escenas para el Patrimonio.
Alfonso Martín Delgado habló de la importancia de los materiales expositivos en su conferencia Materiales y elementos expositivos, apoyándose especialmente en el trabajo recientemente desarrollado por su estudio de arquitectura en el Museo Picasso Málaga, y completando su intervención con una visita guiada por él a dicho Museo, para ver sus realizaciones sobre el terreno.

José $\mathrm{M}^{\mathrm{a}}$ Rueda -Empresa Integral de Arte y Exposiciones-, en su conferencia El montaje de exposiciones como forma de creación espacial, planteó el tema del diseño de los espacios expositivos entendidos no sólo como contenedores de obras, sino como Instalaciones con valor artístico propio.

En la conferencia Guión y diseño de exposiciones. Últimas experiencias. El montaje Pertegaz, Juan Ignacio Macua de Aguirre, director del Equipo Diseño Macua-García Ramos, hizo un recorrido por los elementos y factores por tener en cuenta en la elaboración de guiones y diseños expositivos, ejemplificándolo especialmente con unos de los últimos trabajos de su Equipo: la exposición dedicada a Pertegaz en el Museo Reina Sofía.

El marco final de las jornadas se desarrolló en el Museo Picasso Málaga, con la conferencia, y posterior visita comentada al Museo, de su director, Bernardo Laniado-Romero, que expuso los cambios e innovaciones introducidos en las salas de exposición, tras un año de andadura.

Rosa Domínguez González

Coordinadora cientifica 